\title{
Viroids and their Mode of Parasitism - A Review
}

\author{
Shugufta Parveen ${ }^{1}$, Sheikh Bilal ${ }^{1}$, K.A. Bhat ${ }^{1 *}$, T.A. Shah ${ }^{1}$, Vaseem Yousuf $^{2}$, \\ M. Ashraf. Bhat ${ }^{3}$, F.A. Bhat ${ }^{1}$, T.A. Wani ${ }^{1}$, M.N. Mugal ${ }^{1}$ and Uzma Rahid ${ }^{1}$ \\ ${ }^{1}$ Division of plant pathology, Faculty of Agriculture Wadura, Sher-e -Kashmir University of \\ Agricultural Sciences and Technology of Kashmir, India \\ ${ }^{2}$ K.V.K., Budgam. Sher-e-Kashmir University of Agricultural Sciences and \\ Technology of Kashmir, India \\ ${ }^{3}$ Division of GPB, Faculty of Agriculture Wadura, Sher- $e$-Kashmir University of Agricultural \\ Sciences and Technology of Kashmir, India \\ *Corresponding author
}

\section{A B S T R A C T}

Viroids are plant sub viral pathogens with small, circular, single stranded and non-protein coding RNA genome that are currently known to infect only plants. These are the smallest self-replicating genetic units. These small RNAs contain all the information necessary to mediate replication, pathogenicity, intracellular and systemic trafficking. All or most of

\section{Keywords}

Viroids, Viroid replication,

Trafficking, RNA structural motif, RNA silencing

\section{Article Info}

Accepted:

15 January 2018

Available Online:

10 February 2018 these functions likely result from direct interactions between distinct viroid RNA structural motifs and host cellular factors. The role of these motifs in overall biology of host viroid interactions have been studied in pospiviroidae and avsuniviroidae. Structural motif comprises nucleotides $\mathrm{U} 43 / \mathrm{C} 318$ that form a small loop is required for trafficking from the bundle sheath into the phloem in Potato spindle tuber viroid (PSTVd). In Peach latent mosaic viroid (PLMVd) RNA with a specific structural motif of 12 to 13 nucleotides in left terminal folds into a hairpin, inhibits chloroplast development and results in complete albino phenotype by impairing transcription and translation of plastid rRNA and plastid encoded proteins respectively. Several experiments support that viroids trigger RNA silencing in their hosts. It is hypothesized that viroid-derived small RNAs (vd-siRNAs) targeting specific host DNA or mRNA sequences for transcriptional or posttranscriptional gene silencing respectively leads to viroid pathogenicity. Further research is needed to find out the role of all the structural motifs involved in establishment of infection, defense mechanism by plants against viroid, entry and exit in nucleus and chloroplast, participation of host proteins in specific steps replication, trafficking and molecular basis of viroid host range.

\section{Introduction}

Viroids are plant sub viral pathogens with small, circular, single stranded and nonprotein coding RNA genome (Flores et al.,
2004), that replicate autonomously when inoculated into certain higher plants. Their genome consists of 246-401 nucleotides (Navaro et al., 2012). The first viroid, potato spindle tuber viroid (PSTVd), was discovered 
in the late 1960s-early 1970s (Diener, 1971). Viroids are restricted to higher plants including dicots and monocots, many of them induce symptoms ranging from moderate to severe form (Kovalskaya and Hammond, 2014). They have a worldwide distribution and are the etiologic agents of diverse diseases affecting food, industrial and ornamental (herbaceous and ligneous) plants. Viroidinduced symptoms range from necrosis to less severe developmental disorders, including leaf chlorosis, stunting, flowering alterations and fruit and seed deformations (Gustavo et al., 2009). Viroids of horticulture species are transmitted mainly by vegetative propagation and in plants propagated via seeds, they may be transmitted either mechanically or through seed or pollen, with only tomato planta macho viroid (TPMVd) known to be aphid transmissible under specific ecological conditions (Flores, 2005). Detection is done by Nucleic acid hybridization RT-PCR, biological assays etc (Owens et al., 2012). Viroids are classified into two families: the Pospiviroidae, which replicate in the nucleus, and the Avsunviroidae, which replicate in the chloroplast (Tsagris, 2008). Viroids replicate through an RNA-based rolling-circle mechanism with three steps that, with some variations, operate in the strands of both polarities: i) synthesis of longer-than-unit strands catalyzed by a host nuclear or chloroplastic RNA polymerase that reiteratively transcribes the initial circular template, ii) processing to unit-length, which remarkably is mediated by hammerhead ribozymes in the family Avsunviroidae, and iii) circularization resulting from the action of an RNA ligase or occurring autocatalytically (Flores, 2009) Experimental evidence indicating how viroids infect their hosts in a systemic manner was first provided by Palukaitis (1987), who identified the phloem as the pathway for long-distance movement of potato spindle tuber viroid (PSTVd), a result later confirmed by in situ hybridization (Zhu et al., 2001). The infection process followed by viroids is assumed to involve: (i) intracellular movement to access their subcellular replication site, with the viroid progeny then moving through the cytoplasm; (ii) cell-to-cell movement via plasmodesmata and entry into the phloem; (iii) long-distance movement within the phloem to reach distal plant parts; and (iv) exit from the phloem to invade non-vascular cells (reviewed by Flores et al., 2005; Ding and Wang, 2009). The movement of viroids within their hosts has been addressed in herbaceous hosts (Qi et al., 2004; Zhong et al., 2007; Takeda et al., 2011). Unlike viruses, these plant pathogenic RNAs lack the capacity to code for proteins and, therefore, the viroid life cycle is strictly dependent on host factors. The nontranslatable nature of their genomic RNA has made viroids a very attractive model system for analysing different aspects of RNA biology (Owens, 2007). Studies on viroids have significantly contributed to the progress of understanding the RNA structure-function relationships and the peculiarities of the RNA world (Flores, 2004, 2005; Ding, 2009). In contrast to viruses, which parasitize primarily the translation machinery of their hosts, viroids parasitize host transcription by subverting the template specificity of either the nuclear RNA polymerase II (family Pospiviroidae) or one of the RNA polymerases found in plastids (family Avsunviroidae) to accept RNA templates(Ding, 2009: Flores, 2005, 2011). Additionally, the specificity of DNA ligase 1 is subverted to act upon RNA substrates by viroids in the family Pospiviroidae (Nohales, 2012). However, how these noncoding pathogenic RNAs alter the host development and physiology to induce disease symptoms is still an unsolved question. It has long been accepted that genomic RNA acts as the primary pathogenic effector via a direct interaction between specific viroid motifs and unknown cellular factors. This hypothesis has been mainly 
sustained by the identification of a pathogenicity-modulating RNA motif on the viroid molecule and by the observation that minor changes on the viroid sequence can provoke dramatic effects on the host's disease symptoms. It was postulated that host proteins and/or RNA molecules could be the viroidinteracting factors (Gustavo, 2009). Several earlier studies (Itaya, 2004; Martínez, 2002; Matoušek, 2007) had shown that viroid infected plants contain small RNAs derived from the invading viroid genome, showing that viroids induce disease by RNA silencing.

RNA silencing is a sequence-specific RNA degradation process directed by 21-24 nt small RNAs (sRNAs) processed by Dicer-like (DCL) endonucleases from double-stranded RNA (dsRNA) or self-complementary hairpin RNA (hpRNA) structures (Baumberger and Baulcombe, 2005; Brodersen and Vionnet, 2006). The diced sRNAs are loaded onto an Argonaute (AGO) protein that forms the catalytic core of RNA-induced silencing complex (RISC). AGO-loaded sRNAs are used as guides by RISC to bind to and subsequently degrade cognate single-stranded RNAs, and in plants this is predominantly via an AGO-mediated RNA cleavage-based mechanism of RNA silencing (Baumberger and Baulcombe, 2005; Liu et al., 2007; Rand et al., 2005). Viroid are associated with more than 40 diseases, among which Potato spindle tuber, Coconut cadang cadang, Tomato bushy top, Citrus exocortis, Apple scar skin are economically important.

\section{Structure of viroid}

Viroids are classified into two families on the basis of three major features: 1. Sub-cellular localization and replication site. 2. Presence of absence of hammerhead ribozymes and 3 . Structural properties (Kovalskaya, Hammond, 2014). On the basis of structure viroids are classified into two groups:

\section{Pospiviroidae}

They are folded into compact rod-shaped secondary structure due to high degree of sequence complementarity of their genome(Flores, et al., 2004) they also have highly conserved regions in their genome. Whole structure has been divided into Five broad structural domains which include the left-terminal, pathogenicity, central, variable, and right-terminal domains (Keese and Symons 1985) (Figure 1). For example Potato spindle tuber viroid (PSTVd)

\section{Avsunviroidae}

Self-cleaving viroids which exist as rodshaped molecules and form hammerhead structures in both of their polarity strands (Fig. 2). For example Avocado sun blotch viroid (ASBVd). They replicate in chloroplast. The predicted structure of eggplant latent viroid showed a quasi-rod like conformation with the presence of two bifurcations at the terminal domains (Fadda et al., 2003).

\section{Viroid structural motif}

An ordered and stacked array of non-WatsonCrick base pairs folding into a distinct threedimensional structure. X-ray crystal and nuclear magnetic resonance (NMR) studies demonstrates that most RNA loops and bulges are highly structured three-dimensional (3D) motifs formed via non-Watson-Crick base pairing, base stacking, and other base interactions, that likely serve as the major sites for RNARNA,RNA-protein, and RNA-small ligand interactions (Leontis, 2006) (Fig. 3). Zhong et al., (2008) postulated that most, if not all, of the loops/bulges in the rod-shaped secondary structure of PSTVd represent structural motifs that have distinct functions in replication and/or trafficking. The increasing RNA structural information, however, can be tapped to develop computational tools for 
structural prediction. The various functions performed by motifs are replication, pathogenicity and movement.

\section{Functions of structural motifs}

\section{Replication}

Replication takes place in two organelles i.e., nucleus and chloroplast of cell

\section{Pospiviroidae}

Viroids in the family Pospiviroidae replicate in nucleus, and enter in the nucleus by a carrier mediated mechanism. These viroids replicate by an asymmetric rolling circle mechanism (Branch, 1984; Flores, 2014) (Fig. 4). In this mechanism the (+)-circular RNA is first transcribed into concatemeric linear (-)strand RNA in the nucleoplasm. This long RNA then acts as the replication intermediate for the synthesis of concatemeric, linear (+)strand RNA.

In one scenario, the latter is transported into the nucleolus, where it is cleaved into unitlength monomers and subsequently circularized via intramolecular end-to-end ligation. Alternatively, the cleavage and ligation occur in the nucleoplasm, and the mature viroid RNA is transported into the nucleolus (Qi and Ding, 2003). Initiation and elongation occurs by involvement of host RNA polymerase II. Two lines of evidence support that the enzyme catalyzing elongation of PSTVd and closely-related viroids is RNA polymerase II: i) nanomolar concentrations of the fungal toxin $\alpha$-amanitin that typically inhibit this enzyme also block in vivo and in vitro transcription of (+) and (-) viroid strands, and ii) viroid (+) and (-) strands have been retrieved with a monoclonal antibody against the carboxy-terminal domain of the largest subunit of RNA polymerase II (Flores, 2005).Cleavage of oligomeric (+) strands is most likely mediated by a member of the RNase III family (Bernstein, 2001; Macrae, 2007) Ligation of monomeric linear (+) strands occurs by participation of a novel RNA ligase(Branch, 1982; Wang, 2006).

Identification and subcellular localization of the enzymes involved in cleavage and ligation should help distinguish between these different pathways of processing. Examination of the overall patterns reveals that the loops most critical for replication in single cells reside in the distal end of the left terminal domain and the central region. Specifically, enlarging loop 1, deleting loops 2 and 3 , and closing loop 4 in the left terminal domain reduced replication to below $16 \%$, and disruption of loop 15 (loop E) and loop 13 in the central region reduced replication to 5 to $10 \%$ of the wild-type level (Zhong et al., 2008) (Fig. 4). These low levels of replication indicate that presence of each of these loops is critical for replication.

\section{Avsunviroidae}

They replicate by a symmetric rolling-circle mechanism (Daros et al., 1994; Hutchins et al., 1985 Flores et al., 2014).This model is founded in results obtained with ASBVd (Flores,2000, 2005) additionally supported with data generated with the other members of the family: Peach latent mosaic viroid (PLMVd) (Hernández, 1992) and Eggpant latent viroid (ELVd) (Fadda, 2003). Viroids in the family Avsunviroidae replicate in the chloroplast via an endogenous RNA import pathway yet to be identified Within the chloroplast, these viroids replicate via asymmetric rolling circle mechanism ((Navarro et al., 1999) (Fig. 5). The circular (+)-genomic RNA is first transcribed into a linear, concatemeric (-)-strand RNA. This RNA is cleaved into unit-length molecules and circularized to serve as the template to generate linear, concatemeric (+)-strand RNA. 
This RNA is subsequently cleaved into unitlength monomers and circularized. Therefore, the second half of the cycle is symmetric with respect to the first. Most importantly, cleavage of the oligomeric RNA intermediates is autocatalytic and mediated by hammerhead ribozymes embedded in both polarity strands (Flores, 2001, 2014). The chloroplast has two DNA-dependent RNA polymerases, the single-unit enzyme encoded by the nucleus nuclear encoded plastid RNA polymerase (NEP) and the multiunit enzyme encoded by the chloroplast plastid encoded RNA polymerase (PEP) which help in replication(Navarro, 2000). Cleavage of oligomeric (+) and (-) strands is mediated by hammerhead ribozymes (De la Peña, 2003; Khvorova, 2003).

\section{Movement}

Viroid utilize the endogenous trafficking system to spread within a plant to establish systemic infection (Flores et al., 2005; Lucas, 2006; Ding and Itaya, 2007). The infection process followed by viroids is assumed to involve: (i) intracellular movement to access their subcellular replication site, with the viroid progeny then moving through the cytoplasm; (ii) cell-to-cell movement via plasmodesmata and entry into the phloem; (iii) long-distance movement within the phloem to reach distal plant parts; and (iv) exit from the phloem to invade non-vascular cells (Flores et al., 2005; Ding and Wang, 2009).

To establish a systemic infection, viroid RNAs must traffic from initially infected cells into neighboring cells and further into distant organs. Current evidence indicates that cell-to cell and long-distance trafficking is regulated, notably by the association of specific PSTVd structural motifs with trafficking of the viroid between specific cell types. The first hint for regulated trafficking of viroid RNAs came from the demonstration that two mutations in the right-terminal domain of PSTVd do not affect replication when inoculated by agro infiltration in tomato roots, but appear to affect systemic infection (Hammond, 1994). Some cellular factors with a potential role in viroid trafficking have also been identified (Ding, 2009). The viroid RNA structure consists of different loops and bulges, flanked by double-stranded segments, which give rise to potential RNA motifs that can serve as guiding signals for their intra- and intercellular movement (Pallas and Gomez, 2017).

\section{Cell-to-cell trafficking}

PSTVd traffics from cell to cell through plasmodesmata (Ding, 1997, 1999). Two PSTVd strains were found to enter the phloem for long-distance transport but were unable to exit the phloem, suggesting regulated cell-tocell trafficking (Zhu, 2002). A PSTVd motif has been identified that is required for trafficking from the bundle sheath into the phloem in $N$. benthamiana. This motif comprises nucleotides U43/C318 that form a small loop (loop 7). A tertiary structural model for the U43/C318 motif was inferred through comparative sequence analysis and comparison with X-ray crystal structures of similar motifs in rRNAs. This motif likely represents a protein-binding site, based on the observations that similar motifs in rRNAs interact with specific proteins (Zhong, 2007).

\section{Long-Distance Trafficking}

Experimental evidence indicating how viroids infect their hosts in a systemic manner was first provided by Palukaitis (1987), who identified the phloem as the pathway for longdistance movement of potato spindle tuber viroid (PSTVd), a result later confirmed by in situ hybridization (Zhu et al., 2001). Several cellular factors that facilitate trafficking of viroid RNAs have been reported. 
Fig.1

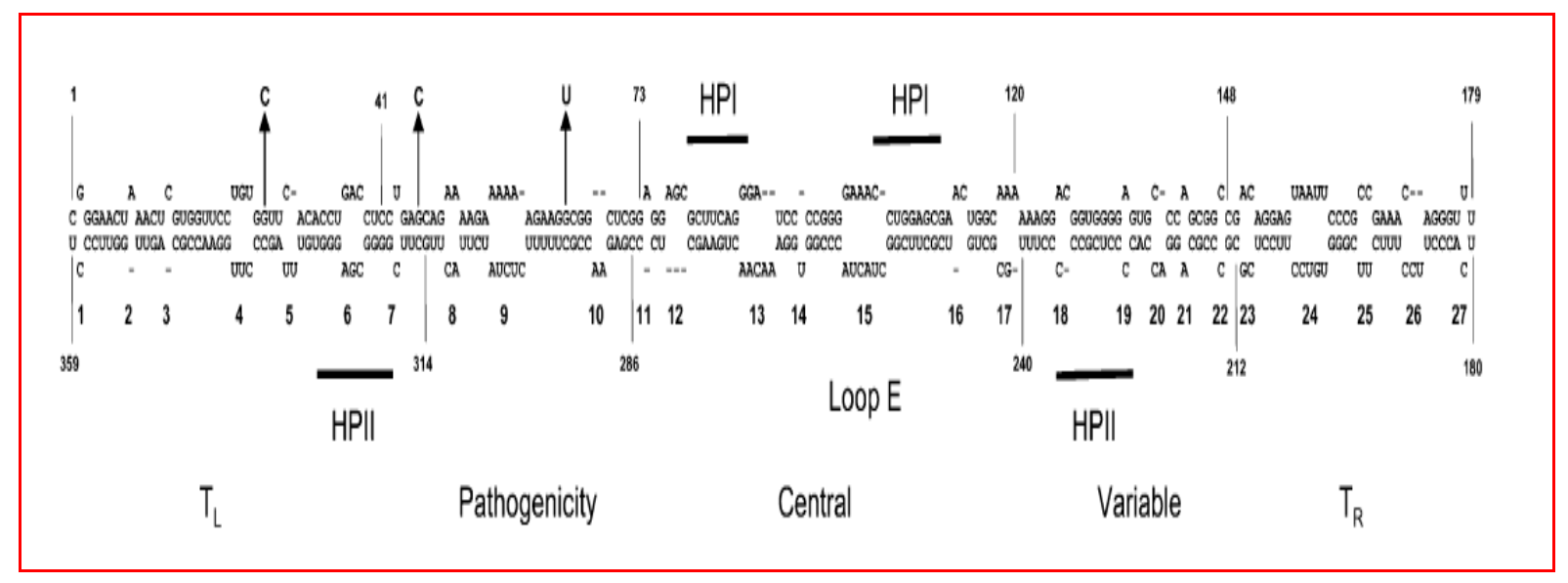

Fig.2

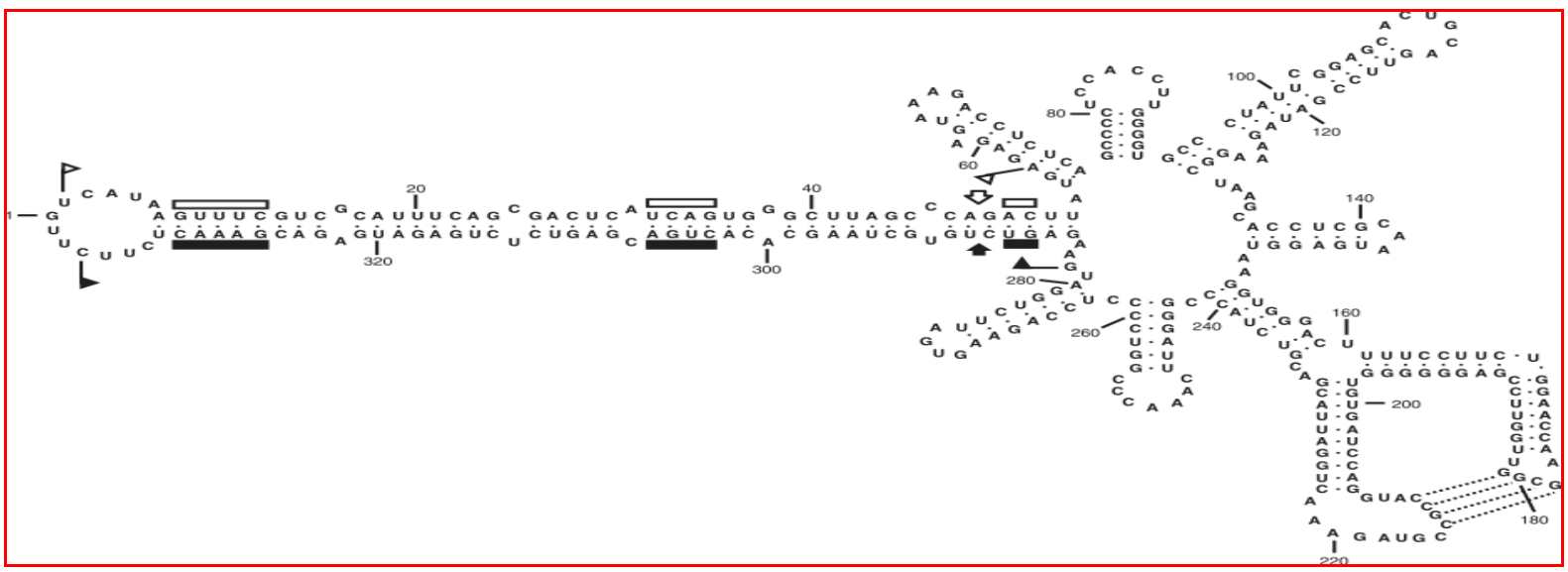

Fig.3
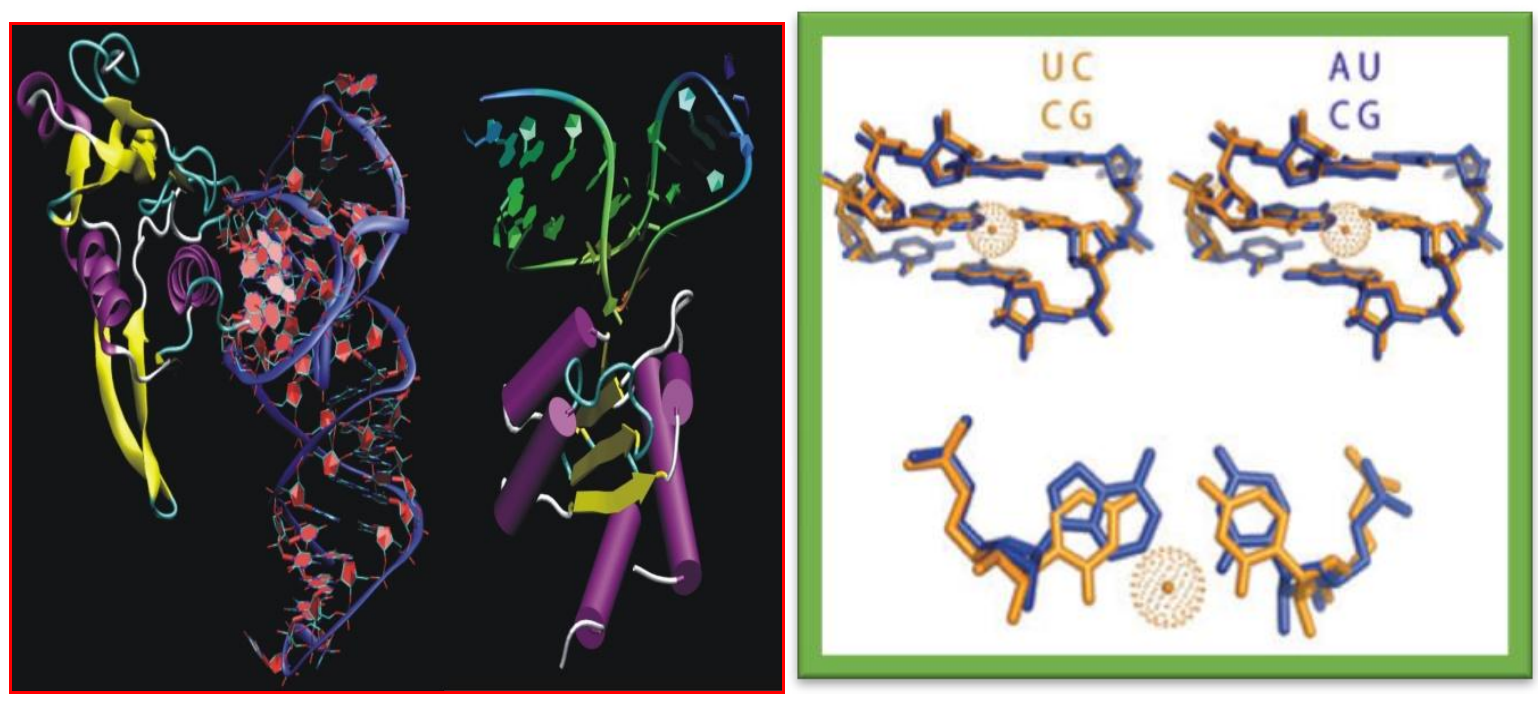
Fig.4
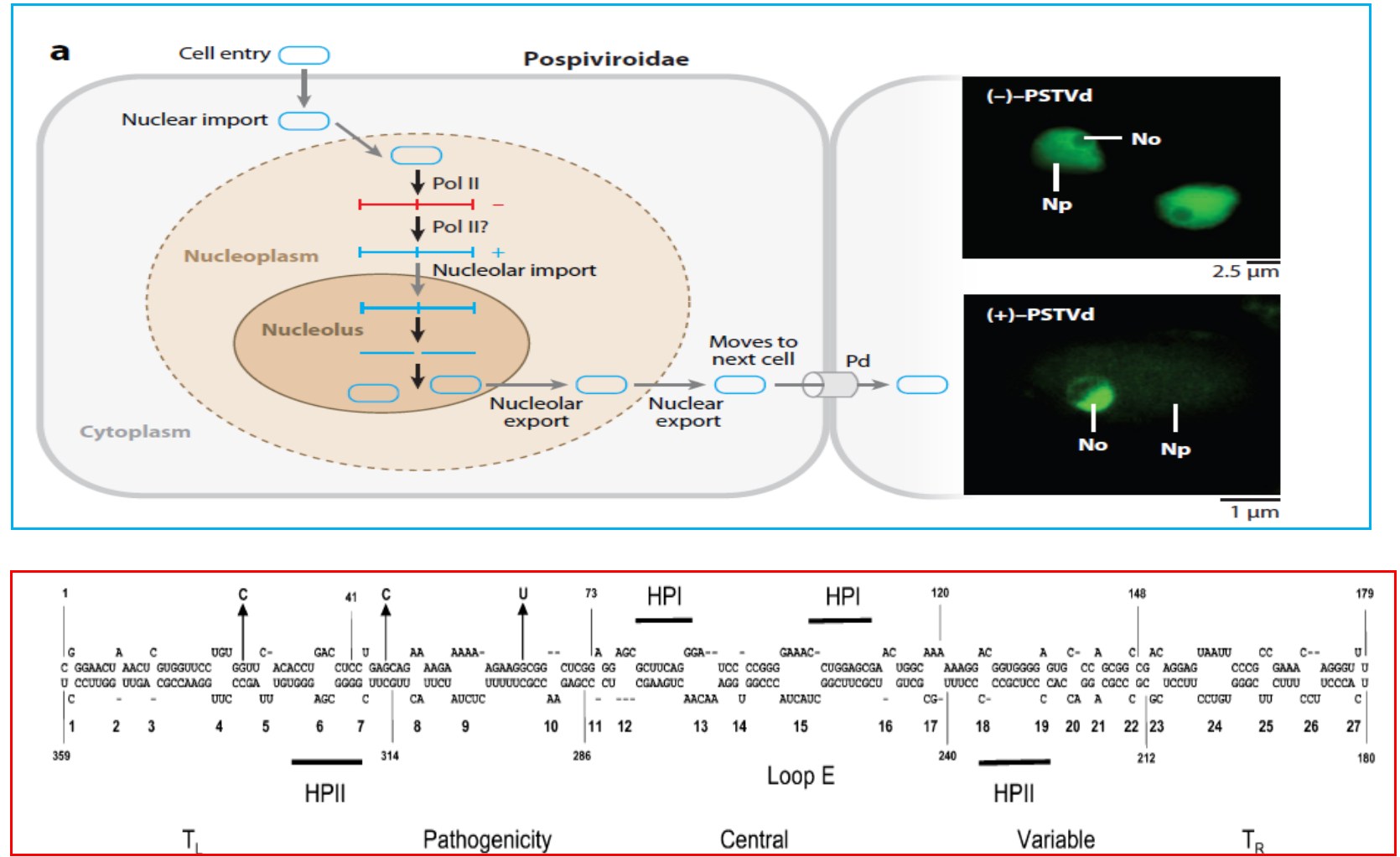

Fig.5
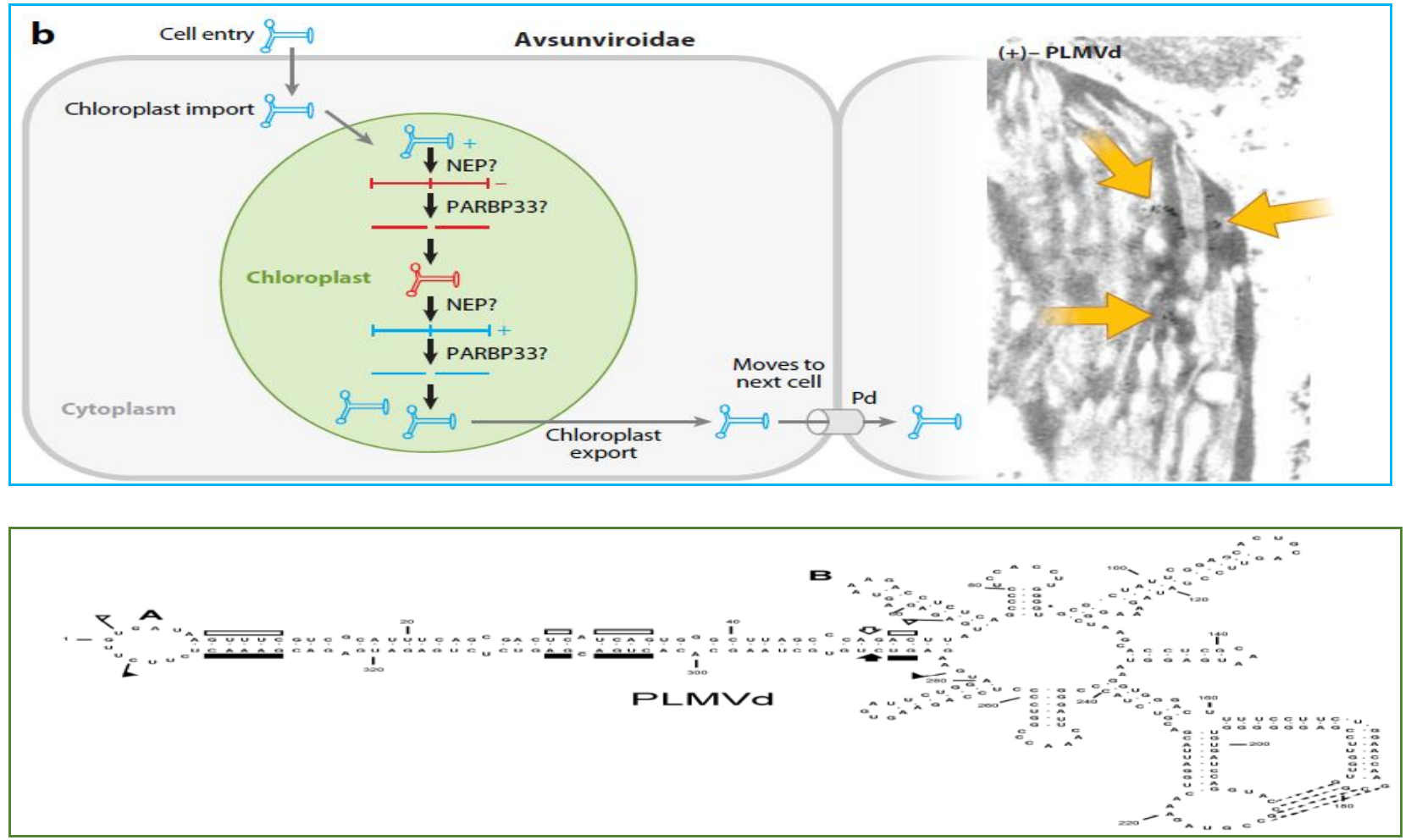
In vitro binding assays showed that the phloem lectin PP2 from cucumber (CsPP2) binds HSVd (Gómez and Pallás, 2001; Owens et al., 2001). Gómez and associates (2005) identified two proteins that bind ASBVd, which include the previously characterized CmmLec17 (Dinant et al., 2003) and a 14$\mathrm{kDa}$ protein which remains to be characterized. CmmLec17 can move long distances from rootstocks to scions in heterografts, suggesting a possible role of this protein in RNA trafficking. Tomato protein known as VIRP1 specifically binds to an AGG/CCUUC. (Gozmanova, et al., 2003; Maniataki, et al., 2003). This motif found in the right terminal domain of PSTVd plays an important role in the long distance movement of pospiviroids in the host vascular system (Loop 24) (Zhong et al., 2008). More recently, the involvement of another protein from tobacco (Nt-4/1), with which PSTVd interacts, has been invoked as well (Solovyev et al., 2013), although its role in viroid movement is not yet clear.

\section{Pathogenesis}

At the cellular level, viroid infection has been associated with disruption/proliferation of the plasma membrane as well as various abnormalities affecting the chloroplast and cell wall. Members of the Avsunviroidae including ASBVd or PLMVd replicate in the chloroplast; thus, their ability to disrupt chloroplast structure, thereby leading to leaf chlorosis and bleaching, is not unexpected (Semancik, 1994; Malfitano, 2003). At the molecular level, the effects of viroid infection on host gene expression have been examined at both the transcriptional and posttranscriptional levels (Owens, and Hammond, 2009). Many of the studies were carried out to identify structural motifs modulating viroid pathogenicity have focused on PSTVd and related viroids. PSTVd and closely-related viroids like Citrus exocortis viroid (CEVd) or
Tomato apical stunt viroid (TASVd) all infect tomato, and when bioassays are carried out using certain sensitive cultivars, infected plants exhibit a characteristic range of symptoms (Ownes, 2009). Two lines of evidence indicate that nucleotides within in the $\mathrm{P}$ domain play an important role in PSTVd symptom induction (Keese, et al., 1985): First, the fact that only 1-2 changes in this portion of molecule are sufficient to dramatically alter symptom expression in tomato second, the association of a larger number of sequence changes restricted mainly to the $\mathrm{P}$ and $\mathrm{V}$ domains of CEVd with similar effects (Visvader and Symons, 1985). For several naturally occurring isolates of PSTVd, thermodynamic calculations indicate that virulence is correlated with the instability of a single structural motif; i.e., the so-called "virulence modulating region" within the $\mathrm{P}$ domain (Owens, and Hammond, 2009). Schnölzer et al., (1985) proposed that PSTVd virulence is determined by the ability of nucleotides within this VM region to interact with one or more unidentified host factors.

The first indication that the molecular mechanism(s) underlying viroid pathogenicity might not be quite so simple came soon thereafter when analysis of CEVd isolates failed to reveal a similar correlation (Visvader and Symons, 1985). To investigate the possible contributions of other structural domains to pathogenicity, Sano and colleagues constructed a series of interspecific chimeras between CEVd and TASVd (Sano, et al., 1992) and examined infected plants for differences in various features of symptom development; e.g., stunting, veinal necrosis, and epinasty. The individual contributions of the TL (terminal left) and $\mathrm{P}$ domains to symptom induction were not completely separable from effects on viroid titer, but sequence differences in the TL domain appeared to have a greater effect on symptom severity than changes in the $\mathrm{P}$ domain. Three 
discrete regions of sequence and/or structural variability were identified that may correspond to these pathogenicity determinants. Characterization of naturallyoccurring variants of several other viroids -Hop stunt viroid (HSVd),Coconut cadangcadang viroid (CCCVd), Avocado sunblotch viroid (ASBVd), Chrysanthemum chlorotic mottle viroid (CChMVd), and PLMVd - has identified still more pathogenicity determinants. HSVd variants isolated from citrus trees exhibiting symptoms of cachexia contain a characteristic cluster of six specific changes in the $\mathrm{V}$ domain (Reanwarakom, and Semancik, 1998, 1999) Artificial passage of CCCVd led to the appearance of a severe lamina-depleting symptom ("brooming") that was associated with sequence changes at three sites in the $\mathrm{P}$ and $\mathrm{C}$ domains (Rodriguez, Randles,1993). Changes were observed at one or two of these sites, but not at all three sites simultaneously. Interestingly, certain of these changes were located just outside the loop E motif of CCCVd, a motif plays an important role in PSTVd replication and pathogenicity.

\section{Role of RNA silencing}

That viroids could exert their pathogenicity through RNA directed gene silencing was proposed by Sänger et al., (1996). The term RNA silencing refers to pan-eukaryotic, sequence-specific RNA-based processes that down regulate gene expression. These regulatory mechanisms act on two levels: (i) transcriptional repression, associated with DNA methylation of promoter regions; and (ii) post-transcriptional regulation, associated with inactivation or degradation of target transcripts The idea that viroids could exert their pathogenicity through RNA silencing was put forward in the last decade triggered by the observation that Potato spindle tuber viroid (PSTVd) replication induces the methylation of homologous cDNA integrated into the genome of transgenic tobacco
(Nicotiana tabacum) plants (Wassenegger, 1994). An emerging hypothesis for viroid pathogenicity is that small RNAs of 21-24 nt, derived from viroid RNA sequences during infection, may guide RNA silencing of host genes and thereby induce disease (Flores, 2004; Markarian, 2004).In support of this hypothesis, there is a positive correlation between the levels of small RNAs and symptom severity for PSTVd (Itaya, 2001; Matoušek, 2007) and ASBVd (Markarian, 2004).

Sequencing analysis of viroid-induced small RNAs in viroid-infected plants have been done or are now extensively underway using several viroid-host combinations such as PSTVdtomato, Itaya, (2007; Machida, 2008) CEVd-tomato (Martín, 2007) and PLMVdpeach. (Patrick, 2009) The analyses revealed that the majority of viroid-specific small RNAs are derived from some restricted regions in the viroid molecule. The latest large-scale nucleotide sequencing analysis on two each of viroids grouped in the family Pospiviroidae; Hop stunt viroid (HSVd) and Grapevine yellow speckle viroid, and in the family Avsunviroidae; CChMVd and PLMVd also confirmed that the large majority of viroid-specific small RNAs of 21 to $24 \mathrm{nt}$ are derived from a few specific regions (hotspots) of the plus and minus strand of viroid RNAs (Navarro, 2009; Di Serio, 2009).

The molecular PTGS triggers are doublestranded RNAs (dsRNAs) and single-stranded RNAs (ssRNAs) with a compact secondary structure that are recognized and processed by specific members of class III RNases (termed Dicer-like, DCL, in plants) (Qi et al., 2005) into small RNAs (sRNAs), mainly microRNAs (miRNAs, of21-22 nt) and small interfering RNAs (siRNAs, of 21, 22 and24 nt) (Axtell, 2013). Some of these (primary) siRNAs activate an amplification circuit catalyzed by a specific host RDR 
(Wassenegger and Krczal, 2006) and DCL, eventually generating mobile secondary siRNAs that ultimately induce systemic(noncell autonomous) RNA silencing(Dunoyer et al., 2010; Molnar et al., 2010) Moreover, one strand of the DCL-generated sRNA duplexes binds specifically to one Argonaute (AGO) protein, forming the core of the RNA Silencing complex (RISC), and direct it to functionally inactivate the complementary RNA (by Cleavage or translation arrest) or DNA (by methylation resulting in transcriptional gene silencing (TGS) (Mallory and Vaucheret, 2010).

The first model to explain the involvement of RNA silencing in the pathogenic processes induced by viroid infection was proposed in 2004(Wang, 2004). In their work, the authors used transgenic tomato (Solanum lycopersicum) plants expressing a partiallength PSTVd. Because the viroid sequence is incomplete, no real infection can take place. However, transgenic plants accumulated viroid specific siRNAs and developed disease symptoms similar to those found in a typical PSTVd infection. The authors suggested that RNA silencing has an important role in viroid pathogenesis and evolution (Wang, 2004). These findings led to the proposal that (vd)si RNAs might act as miRNAs to down regulate the expression of physiologically important host genes and to induce disease-associated symptoms.

\section{Future issues}

There are certain issues which need to be addressed in future, the first being the role of structural motifs in establishment of disease. Also to find whether plants have specific defense mechanisms against viroid infection and their how they evade host degradation system. It is also a challenge for scientists to find the role of host protein in viroid replication and trafficking and to find the mode of entry and exit of viroids from chloroplast. Molecular basis of viroid host range is another challenge which needs to be addressed.

\section{References}

Baumberger, N. and Baulcombe, D.C. 2005. Arabidopsis ARGONAUTE is an RNA Slicer that selectively recruits microRNAs and short interfering RNAs. Proceedings of National Academy of Sciences, 102: 1192811933.

Beatriz, N. and Andreas, G.2012. Viroids: how to infect a host and cause disease without encoding proteins. Biochimie, pp. 1-7

Bernstein, E., Caudy, A.A., Hammond, S.M. and Hannon, G.J. 2001. Role for a bidentate ribonuclease in the initiation step of RNA interference. Nature, 409: 363-366.

Branch, A.D. and Robertson, H.D. 1984. A replication cycle for viroids and other small infectious RNAs. Science, 223:450-55.

Branch, A.D., Robertson, H.D., Greer, C. Gegenheimer, P., Peebles, C. and Abelson, J. 1982.Cell-free circularization of viroid progeny RNA by an RNA ligase from wheat germ. Science, 217: 1147-1149.

Brodersen, P. and Vionnet, O., 2006. The diversity of RNA silencing pathways in plants. Trends in Genetics, 22: 268-280.

De la Peña, M., Gago, S., Flores, R. 2003. Peripheral regions of natural hammerhead ribozymes greatly increase their selfcleavage activity. European Molecular Biology Organization Journal,22: 55615570

Diener, T.O. 1971. Potato spindle tuber "virus" IV. A replicating low molecular weight RNA. Virology, 45: 411-428.

Dinant, S., Clark, A. M., Zhu, Y., Vilaine, F., Palauqui, J. C., Kusiak, C., and Thompson, G. A. 2003. Diversity of the superfamily of phloem lectins (phloem protein 2) in angiosperms. Plant Physiology, 131: 114128.

Ding B, Itaya, A. 2007. Viroid: a useful model for studying the basic principles of infection and RNA biology. Molecular Plant Microbe Interaction, 20: 7-20 
Ding, B. 2009. The biology of viroid-host interactions. Annual Review of Phytopathology,47: 105-131.

Ding, B. and Wang, Y. 2009. Viroids: uniquely simple and tractable models to elucidate regulation of cell-to-cell trafficking of RNA. DNA Cell Biology,28:51-56.

Ding, B., Itaya, A. and Woo, Y. M. 1999. Plasmodesmata and cell-to-cell communication in plants. International Review of Cytology, 190: 251-316.

Ding, B., Kwon, M.O., Hammond, R. and Owens, R. 1997. Cell-to cell movement of potato spindle tuber viroid. Plant Journal, 12: 931-36

DiSerio F., Gisel A., Navarro B., Delgado S.and Martínez de Alba. 2009. Deep sequencing of the small RNAs derived from two symptomatic variants of a chloroplastic viroid: Implications for their genesis and for pathogenesis. PlosONE, 4: 7539.

Dunoyer, P., Schott, G., Himber, C., Meyer, D., Takeda, A., Carrington, J.C., Voinnet, O., 2010. Small RNA Duplexes function as mobile silencing signals between plant cells. Science, 328: 912-916

Fadda, Z., Dora, J.A., Fagoga, C., Flores, R. and Duran Vila, N.K. 2003.Eggplant latent viroid, the candidate type species for a new genus within the family Avsunviroidae (hammerhead viroids. Journal of Virology, 77: 6528-6532.

Flores, R., Delgado, S., Gas, M., Carbonell, A. and Molina, D. 2004. The minimal noncoding RNAs with autonomous replication. Viroids, 567: 42-47

Flores, R., Di Serio, F., Navarro, B., Duran-Vila, $\mathrm{N}$ and Owens, R.A. 2011 Viroids and viroid diseases of plants. In: Hurst CJ (ed) Studies in viral ecology 1 microbial and botanical host systems. New Jersey USA, Wiley \& Sons Inc Hoboken, pp. 307-342.

Flores, R., Gas, M. E., Serrano, D. M., Nohales, M.A., Carbonell, A., Gago, S., De la Peña, $M$ and Daròs, J.A. 2009. Viroid Replication: Rolling-Circles, Enzymes and Ribozymes Viruses, 1: 317-334.

Flores, R., Hernandez, C., Alba, E.M.A., Daros, J. A. and Serio, F. D.2005. Viroids and viroid-host interactions. Annual reviews of phytopathology, 43: 117-39.
Gómez, G., Pallás,V. 2001. Identification of an in vitro ribonucleoprotein complex between aviroid RNA and a phloem protein from cucumber plants. Molecular Plant-Microbe Interaction, 14: 910-913.

Gómez, G., Torres, H., and Pallás, V. 2005. Identification of translocatable RNAbinding phloem proteins from melon, potential components of the long-distance RNA transport system. Plant Journal, 41: 107-116.

Gozmanova, M., Denti, M. A., Minkov, I. N., Tsagris, M., and Tabler, M. 2003. Characterization of the RNA motif responsible for the specific interaction of potato spindle tuber viroid RNA (PSTVd) and the tomato protein Virp1. Nucleic Acids Research, 31: 5534-5543.

Gustavo, G., German, M. and Vicente, P.2009. Interplay between viroid-induced pathogenesis and RNA silencing pathways. Trends in Plant Science, 14: 264-269

Hammond, R. W. 1994. Agrobacterium-mediated inoculation of PSTVd cDNAs onto tomato reveals the biological effect of apparently lethal mutations. Virology, 201: 36-45.

Hernández, C., Flores, R. Plus and minus RNAs of peach latent mosaic viroid self-cleave in vitro via hammerhead structures. 1992. Proceedings of National Academy of Sciences, 89: 3711-3715.

Itaya, A., Folimonov, A., Matsuda, Y., Nelson, R.S., Ding, B. 2001. Potato spindle tuber viroid as inducer of RNA silencing in infected tomato. Molecular Plant-Microbe Interaction, 14: 1332-1334.

Itaya, A., Zhong, X., Bundschuh, R., Qi, Y., Wang, Y. and Takeda R. 2007A structured viroid RNA serves as a substrate for dicerlike cleavage to produce biologically active small RNAs but is resistant to RNAinduced silencing complex-mediated degradation. Journal of Virology, 81: 298094.

Keese, P. and Symons, R.H. 1985. Domains in viroids: evidence of intermolecular RNA rearrangements and their contribution to viroid evolution. Proceedings of National Academy of Sciences, 82: 4582-86.

Keese, P. and Symons, R.H. 1985. Domains in viroids: Evidence of intermolecular RNA 
rearrangements and their contribution to viroid evolution. Proceedings of National Academy of Sciences, 82: 4582-4586.

Khvorova, A., Lescoute, A., Westhof, E. and Jayasena, S.D. 2003. Sequence elements outside the hammerhead ribozyme catalytic core enable intracellular activity. Natural Structure and molecular Biology, 10: 708712.

Kovalskaya, N. and Hammond, R.W. 2014. Molecular biology of viroid-host interaction and disease control strategies. Plant Sciences, 228: 48-60.

Leontis, N.B., Lescoute, A. and Westhof, E. 2006. The building blocks and motifs of RNA architecture. Current Opinion in Structural Biology, 16: 279-87.

Liu, X., Park, J.K., Jiang, F., Liu, Y., McKearin, D. and Liu, Q. 2007. Dicer-1, but not Loquacious, is critical for assembly of miRNA-induced silencing complexes. RNA, 13: 2324-2329

Lucas, W.J. 2006. Plant viral movement proteins: agents for cell-to cell trafficking of viral genomes. Virology, 344: 169-184.

Machida, S., Shibuya, M. and Sano T. 2008. Enrichment of viroid small RNAs by hybridization selection using biotinylated RNA transcripts to analyze viroid induced RNA silencing. Journal of General Plant Pathology, 74: 203-7

Macrae, I.J. and Doudna, J.A. 2007. Ribonuclease revisited: structural insights into ribonuclease III family enzymes. Current Opinion of Structural Biology, 17: 1-8.

Malfitano, M., Di Serio, F., Covelli, L., Ragozzino, A., Hernández, C., Flores, R. 2003. Peach latent mosaic viroid variants inducing peach calico (extreme chlorosis) contain a characteristic insertion that is responsible for this symptomatology. Virology, 313: 492-501.

Mallory, A. and Vaucheret, H. 2010. Form, function, and regulation of ARGONAUTE proteins. Plant Cell, 22: 3879-3889.

Maniataki, E., Martínez de Alba, A. E., Gesser, R. S., Tabler, M., and Tsagris, M. 2003. Viroid RNA systemic spread may depend on the interaction of a 71-nucleotide bulged hairpin with the host protein VirP1. RNA, 9: 346-354.
Markarian, N., Li, H. W., Ding, S. W. and Semancik, J. S. 2004. RNA silencing as related to viroid induced symptom expression. Archives of Virology, 149: 397406

Markarian, N., Li, H.W., Ding, S.-W., Semancik, J.S. 2004. RNA silencing as related to viroid induced symptom expression. Archives of Virology, 149: 397-406.

Martín R, Arenas C., Daròs, J.A., Covarrubias A., Reyes, J. L. and Chua, N. H. 2007.Characterization of small RNAs derived from citrus exocortis viroid (CEVd) in infected tomato plants. Virology, 367: $135-46$.

Martínez de Alba, A.E., Flores, R. and Hernández, C. 2002. Two chloroplastic viroids induce the accumulation of the small RNAs associated with posttranscriptional gene silencing. Journal of Virology, 76: 13094-13096.

Matoušek, J., Kozlová, P., Orctová, L., Schmitz, A., Pesina, K., Bannach, O., Diermann, N.,Steger, G. and Riesner, D. 2007. Accumulation of viroid-specific small RNAs and increase in nucleolytic activities linked to viroid-caused pathogenesis. Biological Chemistry, 388: 1-13.

Molnar, A., Melnyk, C.W., Bassett, A., Hardcastle, T.J., Dunn, R. and Baulcombe, D.C. 2010. Small Silencing RNAs in plants are mobile and direct epigenetic modification in recipient cells. Science, 328: 872-875.

Navarro, B., Pantaleo, V., Gisel, A., Moxon S. and Dalmay T. 2009. Deep sequencing of viroid-derived small RNAs from grapevine provides new insights on the role of RNA silencing in plant-viroid interaction. PLoS ONE, 4: 7686.

Navarro, J.A., Daròs, J.A. and Flores, R. 1999.Complexes containing both polarity strands of avocado sunblotch viroid: identification in chloroplasts and characterization. Virology, 253: 77-85.

Navarro, J.A., Vera, A. and Flores, R.A.2000. chloroplastic RNA polymerase resistant to tagetitoxin is involved in replication of avocado sunblotch viroid. Virology, 268: 218-225.

Nohales, M.A., Flores R, Daros, J.A. 2012. A 
viroid RNA redirects host DNA ligase 1 to act as an RNA ligase. Proceedings of National Academy of Sciences, 109: 1380513810.

Owens, R. A. and Hammond, R.W.2009. Viroid Pathogenicity: One Process, Many Faces Viruses, 1: 298-316

Owens, R. A. 2007. Potato spindle tuber viroid: the simplicity paradox resolved. Molecular Plant Pathology, 8:549-560.

Owens, R. A., Blackburn, M., and Ding, B. 2001. Possible involvement of the phloem lectin in long-distance viroid movement. Molecular Plant Microbe Interaction, 14: 905-909.

Owens, R.A., Sano, T. and Duran-vila, N. 2012. Plant viroids: isolation, characterization/detection, and analysis. In: Watson, J., Wang, MB. (Eds). Antiviral Resistance in Plants. Methods in Molecular Biology, 894: 253-271.

Pallas, V. and Gomez, G.2017.Viroid Movement. In: Viroids and Satellites. Pp. 83-91.

Palukaitis, P. 1987. Potato spindle tuber viroid: investigation of the long-distance, intraplant transport route. Virology, 158: 239241.

Patrick St-Pierre, I., Hassen, F., Thompson, D. and Perreault, J. P. 2009.Characterization of the siRNAs associated with peach latent mosaic viroid infection. Virology, 383: 17882.

Qi, Y., Denli, A.M., Hannon, G.J., 2005. Biochemical specialization within Arabidopsis RNA silencing pathways. Molecular Cell, 19: 421-428.

Qi, Y., Ding, B., 2003. Differential subnuclear localization of RNA strands of opposite polarity derived from an autonomously replicating viroid. Plant Cell, 15: 25662577.

Rand, T.A., Petersen, S., Du, F. and Wang, X. 2005. Argonaute 2 cleaves the anti-guide strand of siRNA during RISC activation. Cell, 123: 621-629.

Reanwarakom, K. and Semancik, J.S. 1998. Regulation of pathogenicity in hop stunt viroid related group II citrus viroids. Journal of General Virology, 79: 35813584 .
Reanwarakom, K. and Semancik, J.S. 1999. Correlation of hop stunt viroid variants to cachexia and xyloporosis diseases of citrus. Phytopathology, 89: 568-574.

Rodriguez, M.J. B. and Randles, J.W. 1993. Coconut cadang-cadang viroid (CCCVd) mutants associated with severe disease vary in both the pathogenicity domain and central conserved region. Nucleic Acids Research, 21: 2771.

Sänger, H.L., Schiebel, L., Riedel, T., Pélissier, T. and Wassenegger, M. 1996. The possible links between RNA directed DNA methylation (RdDM), sense and antisense RNA, gene silencing, symptom-induction upon microbial infections and RNAdirected RNA polymerase (RdRP). Proceedings of 8th International Symposium of Molecular Plant Microbe Interactions.

Sano, T., Candresse, T., Hammond, R.W., Diener, T.O. and Owens, R.A. 1992.Identification of multiple structural domains regulating viroid pathogenicity. Proceedings of the Natural Academy of Sciences, 89: 1010410108.

Schnölzer, M., Haas, B., Ramm, K., Hofmann, H. and Sänger, H. L. 1985. Correlation between structure and pathogenicity of potato spindle tuber viroid (PSTV). European Molecular Biology Organization Journal, 4: 2181-2190.

Semancik, J.S. and Szychowski, J.A. 1994. Avocado sunblotch disease: a persistent viroid infection in which variants are associated with differential symptoms. Journal of General Virology, 75: 15431549.

Solovyev, A.G., Makarova, S.S., Remizowa, M.V., Lim, H.S., Hammond, J., Owens, R.A. and Kopertekh, Schieman. J. and Morozov, S.Y. 2013. Possible role of Nt$4 / 1$ protein in macromolecular transport in vasicular tissue. Plant signaling and behavior, 8: 156-173.

Tsagris, E.M. 2008. Viroids. Cell microbiology, 10: 2168-2179.

Visvader, J. E. and Symons, R.H. 1985. Eleven new sequence variants of citrus exocortis viroid and the correlation of sequence with pathogencity. Nucleic Acids Research, 13: 
2907-2920.

Wang, L.K., Schwer, B. and Shuman, S. 2006. Structure-guided mutational analysis of T4 RNA ligase 1. RNA, 12: 2126-2134.

Wassenegger, M., Heimes, S., Riedel, L. and Sänger, H.L. 1994. RNA-directed de novo methylation of genomic sequences in plants. Cell, 76: 567-576.

Wassenegger, M., Krczal, G.,2006. Nomenclature and functions of RNA-directed RNA polymerases. Trends in Plant Sciences, 11: 142-151.

Zhong, X., Archual, A. J., Amin, A.A. and Ding, B. 2008. A genomic map of viroid RNA motifs critical for replication and systemic trafficking. Plant Cell, 20: 35-47.
Zhong, X., Tao X., Stombaugh, J., Leontis, N. and Ding B. 2007. Tertiary structure and function of an RNA motif required for plant vascular entry to initiate systemic trafficking. European Molecular Biology Organization Journal, 26: 3836-46.

Zhu, Y., Green, L., Woo, Y. M., Owens, R. and Ding, B. 2001. Cellular basis of potato spindle tuber viroid systemic movement. Virology, 279: 69-77.

Zhu, Y., Qi, Y., Xun, Y., Owens R. and Ding, B.2002.Movement of potato spindle tuber viroid reveals regulatory points of phloemmediated RNA traffic. Plant Physiology, 130: 138-46.

\section{How to cite this article:}

Shugufta Parveen, Sheikh Bilal, K.A. Bhat, T.A. Shah, Vaseem Yousuf, M. Ashraf. Bhat, F.A. Bhat, T.A. Wani, M.N. Mugal and Uzma Rahid. 2018. Viroids and their Mode of Parasitism A Review. Int.J.Curr.Microbiol.App.Sci. 7(02): 1248-1261. doi: https://doi.org/10.20546/ijcmas.2018.702.153 